\title{
In Vitro Study of the Incorporation and Transport of Nonesterified Fatty Acids into the Phospholipids of the Red Blood Cell Membranes of Cystic Fibrosis Patients
}

\author{
VERA ROGIERS, ${ }^{(37)}$ ISRAËL MANDELBAUM, NAVA MOZES, FRANÇOISE VERTONGEN, \\ ISIDOOR DAB, ROBERT CROKAERT, AND HENRI L. VIS \\ Department of Biochemistry and Pediatrics, Free University Brussels, B-1090 Brussels, Belgium
}

\begin{abstract}
Summary
The in vitro incorporation and transport of plasma nonesterified fatty acids into phospholipids of red cell membranes have been studied in cystic fibrosis and healthy children.

Red blood cells were labeled in vitro by an active "acyltransferase"-dependent incorporation of radioactively labeled nonesterified fatty acids. $\left[{ }^{3} \mathrm{H} \mid\right.$-Palmitic and $\left[{ }^{14} \mathrm{C}\right]$-linoleic acid, bound to albumin, have been studied simultaneously because it has been shown before that the concentration of palmitic acid increases and the concentration of linoleic acid decreases both in the plasma nonesterified fatty acid fraction and in the various phospholipids of the erythrocyte membranes of cystic fibrosis patients.

The labeled cells were reincubated in autologous serum and the radioactivity present in the serum lipids and in the major phospholipid fractions of the erythrocyte membranes was measured.

A general conclusion is that the in vitro turnover of labeled palmitic and linoleic acids in the phospholipids of the erythrocyte membranes is higher for cystic fibrosis patients than for healthy children. No difference is detectable between the in vitro behaviour of $\left[{ }^{14} \mathrm{Cl}\right.$-linoleic versus $\left[{ }^{3} \mathrm{H}\right]$-palmitic acid in cystic fibrosis patients compared with healthy children.
\end{abstract}

\section{Speculation}

It is possible that the primary defect in cystic fibrosis is caused by an alteration in membrane structure and function. Perhaps the increased turnover of erythrocyte fatty acids in cystic fibrosis patients is related to this membrane defect.

The fatty acid patterns of the lipid fractions of plasma $(9,10$, $23)$, platelets (20), red blood cells $(\mathrm{RBC})(4,7,14,24)$, adipose tissue (11), bronchial mucous (27), and sputum (26) from cystic fibrosis (CF) patients are changed in comparison with the corresponding patterns of healthy subjects.

Some investigators have attributed these modifications to malabsorption, occurring in CF patients with pancreatic insufficiency $(9,10)$. Others, however, have suggested a possible defect in fatty acid metabolism $(19,20)$. The results of our previous research support the latter hypothesis, as it showed that abnormal fatty acid patterns can occur in both $C F$ patients with and without pancreatic insufficiency $(8,23)$. Abnormal fatty acid patterns have been found for the nonesterified fatty acid (NEFA) fraction of the CF patients without pancreatic insufficiency studied (23). As this fraction could be more variable than the other plasma lipids, the fatty acid patterns of the plasma cholesterol ester fractions have been analysed for $\mathrm{CF}$ patients without clinical evidence of pancreatic difficulties (8). These fatty acid patterns were abnormal too, although to a lesser extent than the corresponding patterns of $\mathrm{CF}$ patients with pancreatic insufficiency. Nevertheless the con- clusion of that study (8) is that the fatty acid composition of the plasma cholesterol esters of CF patients without pancreatic insufficiency is significantly different from the results obtained for agematched controls (8). Furthermore, it was found that the fatty acid patterns of the various phospholipid fractions of the RBC membranes are abnormal in CF patients with pancreatic insufficiency (24). A positive correlation was observed between the fatty acid changes of both plasma and RBC phospholipid fractions (Rogiers, V., unpublished data).

One of the mechanisms, playing a major role in the continuous in vivo renewal of $\mathrm{RBC}$ lipids consists of the active incorporation of plasma NEFA's into the phospholipids of the RBC membrane $(28,29)$. Consequently it is possible that this process could be partly responsible for the abnormalities observed in the RBC membranes of CF patients. On the other hand, abnormal fatty acid patterns intrinsic to the CF membranes could support the hypothesis of a possible defect in fatty acid metabolism.

In order to obtain more information concerning the active incorporation process of plasma NEFA's into the phospholipids of the RBC membranes of CF patients, a number of incorporation and reincubation experiments with labeled NEFA's have been carried out. RBCs of healthy and CF children were incubated with $\left[{ }^{14} \mathrm{C}\right]$-linoleic and $\left[{ }^{3} \mathrm{H}\right]$-palmitic acid bound to albumin. The labeled RBC's were reincubated in their autologous serum.

In this study, the theoretical approach proposed by Shohet $(28$, 29 ) is used (Fig. 1). The assumption is made that the incorporated NEFA's are all taken up into phosphatidyl choline (PC) before their transfer into phosphatidyl ethanolamine (PE) and their final release into the serum. This reasoning is not completely correct, but it allows to study separately the incorporation of both labeled fatty acids into the PC and the PE fraction. If however, it is assumed that plasma NEFA's are incorporated independently into both PC and PE by the same reaction catalysed by acyltransferase, the final conclusions of this study remain the same. In that case, the results shown in Figures $2 \mathrm{a}, \mathrm{b}$ and Figures $4 \mathrm{a}, \mathrm{b}$ represent the incorporation of both labeled fatty acids into the combined PC $+\mathrm{PE}$ fraction.

A possible influence of the transmethylation pathway in which $\mathrm{PE}$ is transformed into PC via monomethyl and dimethyl phosphatidyl ethanolamine need not to be taken into account in the calculations presented in this study. The activity of the enzymes, responsible for this conversion, is highest in liver microsomes, but it is still the minor pathway in this tissue for the synthesis of PC (32). Calculations, reported in the literature, show that in erythrocytes the enzymatic activity just mentioned is only $0.1 \%$ of that observed in liver microsomes (34).

\section{MATERIALS AND METHODS}

Materials. Materials, used for the analysis of the individual phospholipid fractions of the RBCs, were described previously (22). 


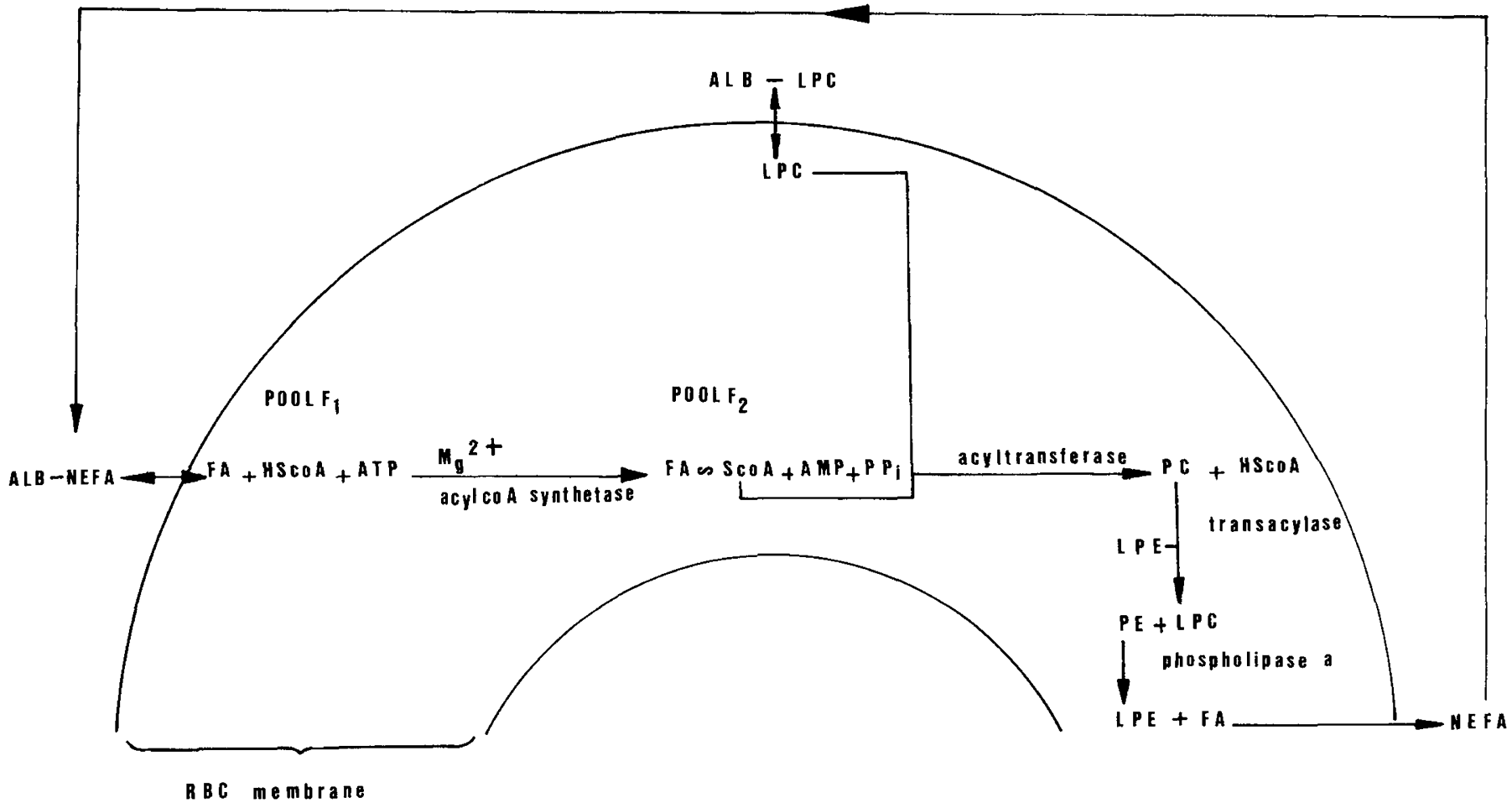

Fig. 1. Fatty acid renewal of the RBC phospholipids in the human erythrocyte. Modification of the scheme, proposed by Shohet (28, 29). NEFA, nonesterified fatty acids; ALB, albumin; $\mathrm{F}_{1}$, superficial pool of NEFA's; $\mathrm{F}_{2}$, deeper membrane pool; PC, phosphatidyl choline; PE, phosphatidyl ethanolamine; LPC, lyso-PC; LPE, lyso-PE; $\leftrightarrow$, passive exchange; and $\rightarrow$, active exchange.

Activated charcoal was obtained from Merck. ATP disodium salt and CoA SH, grade I, trisodium salt were purchased from Boehringer. Human albumin, fraction $V$ was obtained from Sigma. Its fatty acid content was reduced to $0.020 \mu$ mole NEFA/ $50 \mathrm{mg}$ by the method of Chen (5). Di- $\left[1-{ }^{14} \mathrm{C}\right]$-palmitylphosphatidyl choline, specific activity $=118 \mathrm{mCi} / \mathrm{mmole}$ in an ethanol solution; $\left[1-{ }^{14} \mathrm{C}\right]$-linoleic acid, specific activity $=51 \mathrm{mCi} / \mathrm{mmole}$ in an hexane solution and $\left[9,10-{ }^{3} \mathrm{H}\right]$-palmitic acid, specific activity $=$ $500 \mathrm{mCi} / \mathrm{mmole}$ in a benzene/hexane solution were purchased from the Radiochemical Centre. Both fatty acid solutions were evaporated under a gentle stream of $\mathrm{N}_{2}$, neutralised with a calculated amount of $0.5 \mathrm{NaOH}$ and bound to human albumin (solution of $200 \mathrm{mg} \%$ in isotonic $\mathrm{NaCl}$, phosphate buffered at $\mathrm{pH} 7.4$ ). The final fatty acid-albumin solution contained $0.5 \times 10^{8} \mathrm{dpm}\left[{ }^{14} \mathrm{C}\right]-$ linoleic and $2 \times 10^{8} \mathrm{dpm}\left[{ }^{3} \mathrm{H}\right]$-palmitic acid per ml solution.

Scintillation cocktails Carbosorb-Permafluor V $(1 / 3 ; \mathrm{v} / \mathrm{v})$, Monophase 40 and Instagel II were obtained from Packard Instrument Co. Krebs-Henseleit buffer was prepared as described elsewhere (33). Penicillin and streptomycin sulfate were purchased from Continental Pharma.

Blood collection. Twenty $\mathrm{ml}$ and $50 \mathrm{ml}$ venous blood samples were needed respectively for the incorporation and the reincubation experiment. Blood was collected with sodium citrate from four CF patients (two females and two males, 8-10 years old) with pancreatic insufficiency and from four healthy children of the same age and sex after an overnight fast of $12 \mathrm{~h}$.

In vitro experiments: incorporation experiment. Twenty $\mathrm{ml}$ blood are centrifuged at $250 \times g$ for $10 \mathrm{~min}$ at room temperature. White cells and platelet-rich plasma are removed along with the top of the red cell mass. Next the bulk of the RBC is washed three times with two volumes of Krebs-Henseleit buffer, $\mathrm{pH} 7.4$ containing 8 $\mathrm{mM}$ glucose. Seven $\mathrm{ml}$ of the packed RBCs are incubated with $33.3 \mathrm{ml}$ Krebs-Henseleit buffer (+ glucose $8 \mathrm{mM}$ ), $210 \mathrm{mg}$ ATP, $14 \mathrm{mg} \mathrm{CoA} \mathrm{SH}$ and $0.7 \mathrm{ml}$ labeled fatty acid albumin solution at $37^{\circ} \mathrm{C}$ for $3 \mathrm{~h}$ with gentle agitation.

At various time intervals aliquots of the incubation suspensions are taken and centrifuged immediately. The sedimented cells are washed once with isotonic $\mathrm{NaCl}$ solution at $\mathrm{pH} \mathrm{7.4,} \mathrm{three} \mathrm{times}$ with defatted human albumin solution $(200 \mathrm{mg} \%$ in isotonic $\mathrm{NaCl}$, $\mathrm{pH} 7.4$ ) in order to remove surface fatty acids and finally once with isotonic $\mathrm{NaCl}, \mathrm{pH} 7.4$. After $0.1 \mathrm{ml}$ dithionite $(95 \mathrm{mg} / \mathrm{ml}$ water) is added, the $\mathrm{RBCs}$ are stored at $-20^{\circ} \mathrm{C}$ under $\mathrm{N}_{2}$. The total lipids are extracted the next day. These lipid extracts are stored at $-20^{\circ} \mathrm{C}$ under $\mathrm{N}_{2}$ for a maximum of 2 months. 2,6-Ditert-butyl-p-cresol (BHT) is added as antioxidant. The results of a previous study have shown that under these storage conditions no change could be observed in the fatty acid composition of the various phospholipid fractions for at least 4 months. (Rogiers, V.: unpublished data).

In vitro experiments: reincubation experiment. Fifty $\mathrm{ml}$ blood are washed and the RBCs are incubated with radioactively labeled fatty acids for two $h$ as described in "In vitro experiments: incorporation experiment."

Eight $\mathrm{ml}$ packed $\mathrm{RBCs}$ are then resuspended in $8 \mathrm{ml}$ autologous serum for $5 \mathrm{~min}$ at $37^{\circ} \mathrm{C}$ in order to restore the normal surface pool of nonradioactive fatty acids. The serum is removed by centrifugation. Seven $\mathrm{ml}$ of the radioactively labeled $\mathrm{RBC}$ suspension are then reincubated in $10.5 \mathrm{ml}$ autologous serum to which $34.5 \mathrm{mg}$ glucose; $59.1 \mathrm{mg}$ ATP; $5.9 \mathrm{mg} \mathrm{CoA} \mathrm{SH} ; 1.5 \mathrm{mg}$ penicillin and $1.5 \mathrm{mg}$ streptomycin sulfate are added. At various time intervals, aliquots are taken and centrifuged. $\mathrm{RBCs}$ are washed and stored with dithionite at $-20^{\circ} \mathrm{C}$. The next day lipid extracts are made and stored under $\mathrm{N}_{2}$ at $-20^{\circ} \mathrm{C}$ for maximum 2 months.

Lipid analysis. The individual phospholipid fractions of the RBCs are analysed as described recently (22). In short, total lipids are extracted by the method of Rose and Oklander (25). The total extract is then purified by partition-chromatography on Sephadex G 25 coarse and the phospholipids are separated by two dimensional thin layer chromatography (in duplicate). One thin layer chromatographic plate is used for the phosphorus determination of the PC, PE and sphingomyelin (SPm) spots by the method of Bartlett (1). The second thin layer chromatographic plate is used for radioactivity determinations of the $P C$ and $P E$ spots and a phosphorus determination of the SPm spot. The phospholipid composition of the erythrocyte membranes is as published before (24). Namely, the relative concentration of PC and PE is $27 \%$ for 
both groups of children. The fatty acid composition of the plasma NEFA fraction and of the individual phospholipids is determined as described previously $(21,22)$.

Radioactivity determinations. Radioactivity is measured in a Beckmann LS 150 scintillation spectrometer. For serum, Instagel II is the scintillation fluid. $\left[{ }^{3} \mathrm{H}\right]$ and $\left[{ }^{14} \mathrm{C}\right]$ counts are measured with widely separated windows. Automatic quench correction and external standardisation are used.

The PC and PE spots are scraped off into quartz boats. Two tenths of a $\mathrm{ml}$ distilled water and $50 \mathrm{mg}$ mannitol are added. The samples are burned in a "Biological Material Oxidizer" from R. $\mathrm{J}$. Harvey Instrument Co. Combustion of the samples takes place at $900^{\circ} \mathrm{C}$ under a continuous flow of $\mathrm{O}_{2}$. Water is trapped by a mixture of methanol and dry ice. Monophase 40 is the scintillation fluid for $\left[{ }^{3} \mathrm{H}\right] . \mathrm{CO}_{2}$ is taken up in a mixture of Carbosorb and Permafluor V $(1 / 3, \mathrm{v} / \mathrm{v})$.

Calibration of the combustion apparatus is carried out every day and appropriate correction factors are calculated. The recovery of di-[ $\left[1-{ }^{14} \mathrm{C}\right]$-palmitylphosphatidylcholine on silica gel, using this combustion technique is $97.5 \% \pm 2.3$ (S.D.) with $n=12$.

\section{RESULTS}

The results are expressed in $\mathrm{dpm} / \mu$ mole $\mathrm{SPm}$. The latter lipid fraction is used as an internal standard because it is not involved in the NEFA exchange mechanism. Its concentration in the RBC is the same for both $\mathrm{CF}$ and healthy children and remains constant during the incorporation and the reincubation process as experimentally determined. The results are statistically analysed using the Student's $t$ test (two-tailed) according to Snedecor and Cochran (31).

Incorporation experiment: phosphadityl choline. The incorporation of labeled $\left[{ }^{14} \mathrm{C}\right]$-linoleic acid into $\mathrm{PC}$ is shown in Figure 2a and of $\left[{ }^{3} \mathrm{H}\right]$-palmitic acid in Figure $2 b$. The term "incorporation into PC" means the radioactivity that is present in PC plus the one already transferred from PC into PE. From these graphs it appears that during a given period of time more net counts of both labeled fatty acids accumulate in the PC fraction of the erythrocytes for the CF patients than for the healthy children (for $t=3 \mathrm{~h}, P<0.001)$. The difference observed is not due to variation of the $\mathrm{PC}$ concentration because it was found that during the whole experiment the concentration of $\mathrm{PC}$ in the RBC membrane remained constant for healthy children and for $C F$ patients.

The ratio of incorporated $\left[{ }^{3} \mathrm{H}\right]$-palmitic acid into $\mathrm{PC}$ versus incorporated $\left[{ }^{14} \mathrm{C}\right]$-linoleic acid is practically the same for healthy and CF children.

Incorporation experiment: phosphatidyl ethanolamine. Figure 3a and $b$ show the incorporation of $\left[{ }^{14} \mathrm{C}\right]$-linoleic and $\left[{ }^{3} \mathrm{H}\right]$-palmitic acid into $\mathrm{PE}$. The incorporation rate of both fatty acids into $\mathrm{PE}$ is significantly higher for CF patients than for healthy children (for $t=3 \mathrm{~h}, P<0.001$ ). The PE concentration was measured at each time interval. The difference observed is not due to a different concentration of $\mathrm{PE}$ for $\mathrm{CF}$ and healthy erythrocytes.

The ratio of incorporated $\left[{ }^{3} \mathrm{H}\right]$-palmitic acid into $\mathrm{PE}$ versus incorporated $\left[{ }^{14} \mathrm{C}\right]$-linoleic acid is the same for both healthy and CF children.

Reincubation experiment: phosphatidyl choline. During the reincubation of labeled RBC's in autologous serum, the uptake of both labeled fatty acids from a deeper membrane pool of NEFA's into PC continues. This is shown in Figure $4 a$ and $b$. The ordinate represents the sum of the radioactivities present in $P C$, in $P E$, and in the serum. The units are expressed in $\mathrm{dpm} P C / \mathrm{ml} \mathrm{RBC}$.

$$
\mathrm{dpm} \mathrm{PC} / \mathrm{ml} \mathrm{RBC}=\mathrm{dpm} \mathrm{PC} / \mu \text { mole } \mathrm{SPm} \times \mathrm{C}_{\mathrm{SPm}}
$$

$\mathrm{C}_{\mathrm{SPm}}$ represents the mean concentration of $\mathrm{SPm}$ in $1 \mathrm{ml}$ of $\mathrm{RBC}$ suspension, which is the same for CF and healthy children.

From both graphs it appears that for $\mathrm{CF}$ children the in vitro uptake of $\left[{ }^{14} \mathrm{C}\right]$-linoleic and $\left[{ }^{3} \mathrm{H}\right]$-palmitic acid into $\mathrm{PC}$ continues throughout the experiment. For healthy ones this uptake stops after $7 \mathrm{~h}$ of reincubation.

At the start of the experiment the net uptake of both labeled fatty acids into PC is higher for CF patients than for healthy children as could be predicted by the results of the incorporation experiment, phosphatidyl ethanolamine (for $t=0 \mathrm{~h}, P<0.01$ ).

The in vitro uptake of both fatty acids into $\mathrm{PC}$ is at every time interval significantly higher in $\mathrm{CF}$ children than in healthy ones (for $t=19 \mathrm{~h}, P<0.00 \mathrm{l}$ ); however, the starting conditions of the reincubation experiment are different for both groups of children, due to their different behaviour during the previous incorporation step (Fig. 2). When the relative incorporation rate per time interval $(\Delta t)$ is calculated, which means that the uptake of labeled fatty acids into PC at $t=0$ for CF and healthy children is equalized to one, the same conclusion can still be drawn (Fig. 5a and 5b). It is clear that starting from $t=7$, the relative incorporation rate per time interval of both labeled fatty acids is higher for CF children than for healthy ones (for $t=7 \mathrm{~h}, P<0.001$ ).

Reincubation experiment: phosphatidyl ethanolamine. In Figure $6 \mathrm{a}$ and $\mathrm{b}$, the in vitro uptake of both labeled fatty acids into the

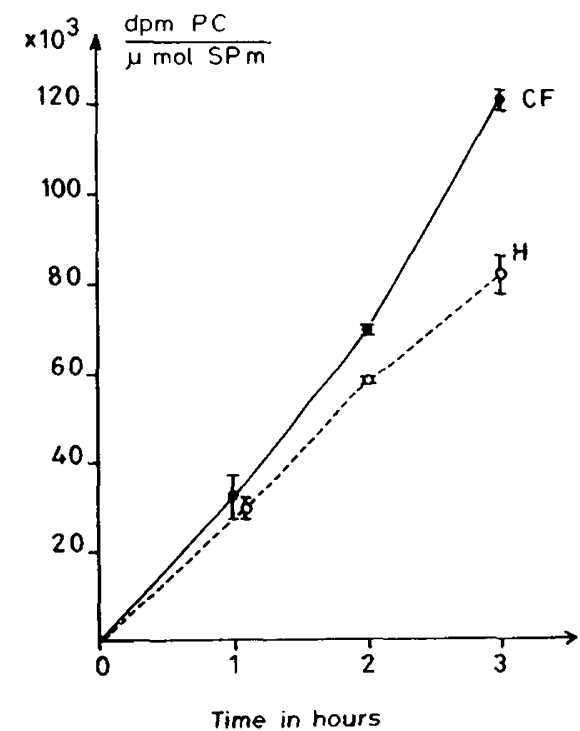

Fig. 2. In vitro incorporation of $\left[{ }^{14} \mathrm{C}\right]$-linoleic acid (left hand panel) and $\left[{ }^{3} \mathrm{H}\right]$-palmitic acid (right hand panel) into the phosphatidyl choline fraction of erythrocyte membranes during the incorporation experiment. -0 , cystic fibrosis (CF) patients and $\mathrm{O}-\ldots \mathrm{O}$, healthy (H) children. The experimental conditions are as described in "Materials and Methods," incorporation experiment. Mean \pm S.D. is indicated $(n=4)$. 

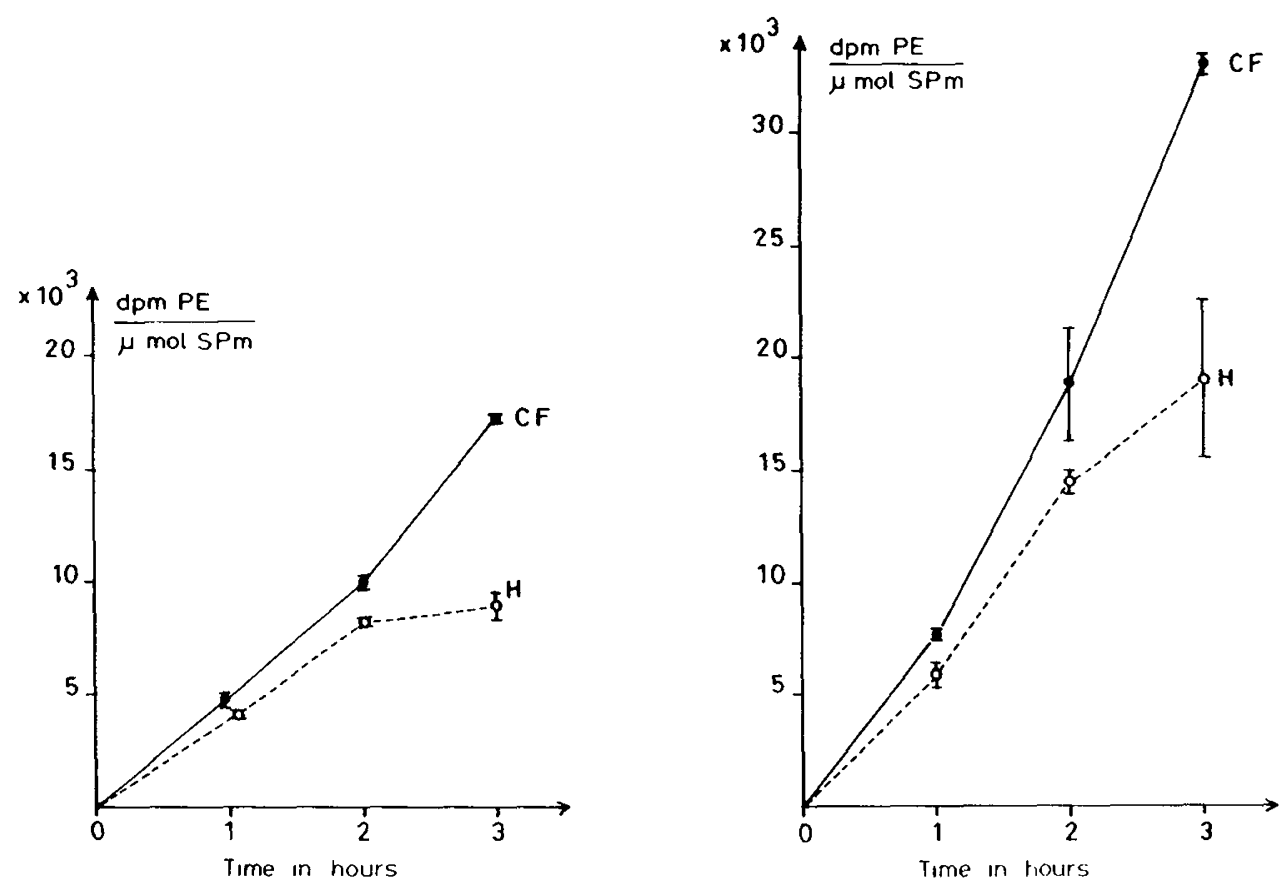

Fig. 3. In vitro incorporation of $\left[{ }^{14} \mathrm{C}\right]$-linoleic acid (left hand panel) and $\left[{ }^{3} \mathrm{H}\right]$-palmitic acid (right hand panel) into the phosphatidyl ethanolamine fraction of the red blood cell membranes, during the incorporation experiment. The results are shown as mean \pm S.D. O-.---O healthy children $(n=4)$. Experimental conditions are as described in "Materials and Methods," incorporation experiment.
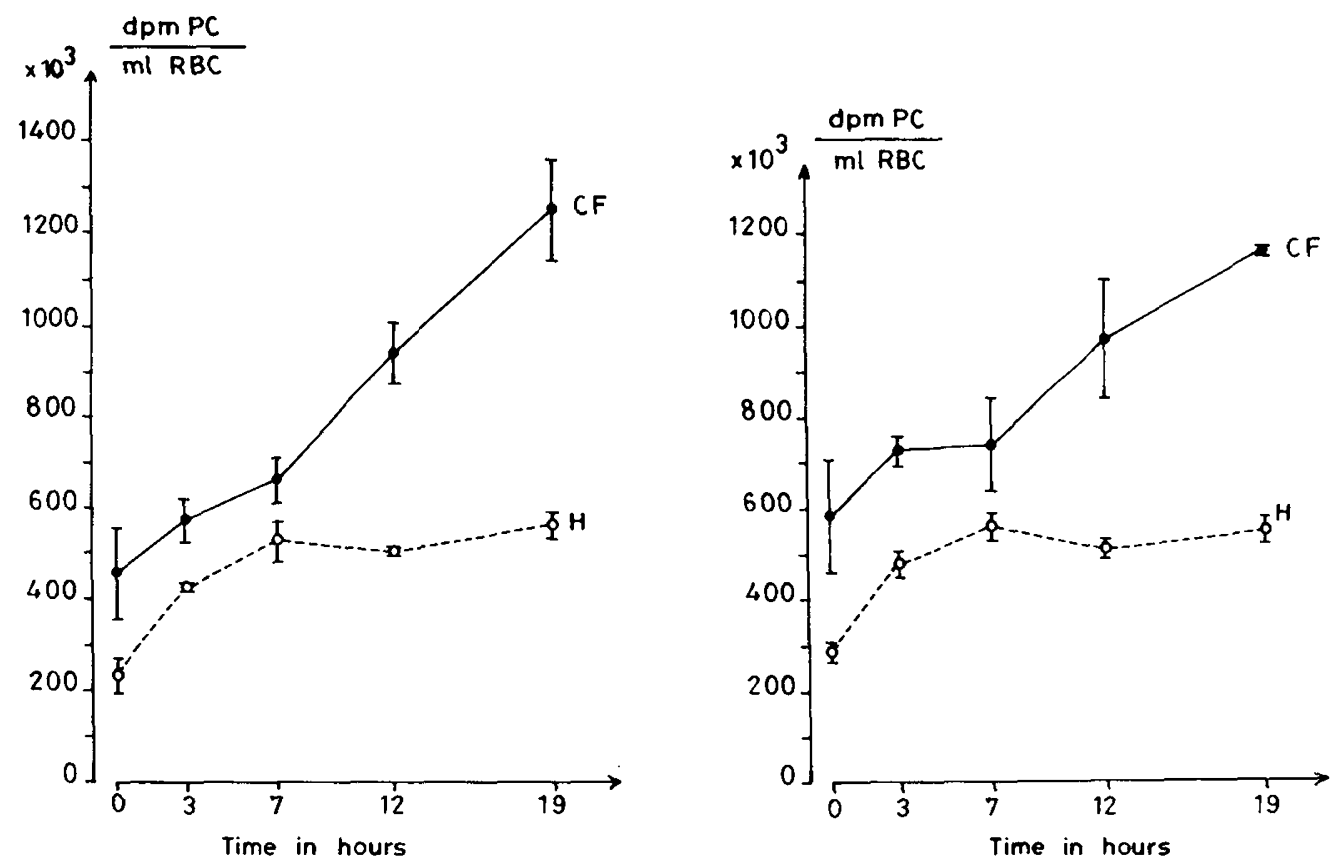

Fig. 4. Further in vitro incorporation of $\left[{ }^{14} \mathrm{C}\right]$-linoleic (left hand panel) and of $\left[{ }^{3} \mathrm{H}\right]$-palmitic acid (right hand panel) into the phosphatidyl choline fraction of erythrocyte membranes during the reincubation experiment. Results are shown as mean \pm S.D. children $(n=4)$. Experimental conditions are as described in "Materials and Methods," reincubation experiment.

erythrocyte $\mathrm{PE}$ fraction is shown. Here again the units are expressed as $\mathrm{dpm} \mathrm{PE} / \mathrm{ml} . \mathrm{RBC}=\mathrm{dpm} \mathrm{PE} / \mu$ mole $\mathrm{SPm} \times \mathrm{C}_{\mathrm{SPm}}$. Because these graphs are equivalent to those represented in Figure $4 \mathrm{a}$ and $\mathrm{b}$, the same conclusions can be drawn. Namely, the transfer of labeled linoleic and palmitic acid from PC into PE is significantly higher for CF cells than for healthy ones (for $t=3 \mathrm{~h}, P<$ $0.001)$.

Reincubation experiment: serum. The in vitro release of $\left[{ }^{14} \mathrm{C}\right]-$ linoleic and $\left[{ }^{3} \mathrm{H}\right]$-palmitic acid from the $\mathrm{RBCs}$ into autologous serum goes on during the whole experiment (Fig. 7a and b). At every moment the release of both fatty acids into serum is signifi- cantly higher for CF children than for healthy ones (from $t=3 \mathrm{~h}$, $P<0.001$ ).

When the relative release rate per time interval of both fatty acids into serum is calculated and when the differences in starting positions between $\mathrm{CF}$ and healthy $\mathrm{RBCs}$ are normalized, it appears that the relative release rate becomes fairly constant after 3 $h$ of reincubation. The relative release rate remains higher for $\mathrm{CF}$ patients than for healthy children (for linoleic acid from $t=7 \mathrm{~h}$, $P<0.001$ and for palmitic acid, $P<0.01$ ).

Reincubation experiment: exchange of $\left[{ }^{3} \mathrm{H}\right]$-palmitic versus $\left[{ }^{14} \mathrm{C}\right]$-linoleic acid. In order to answer the question whether or not 

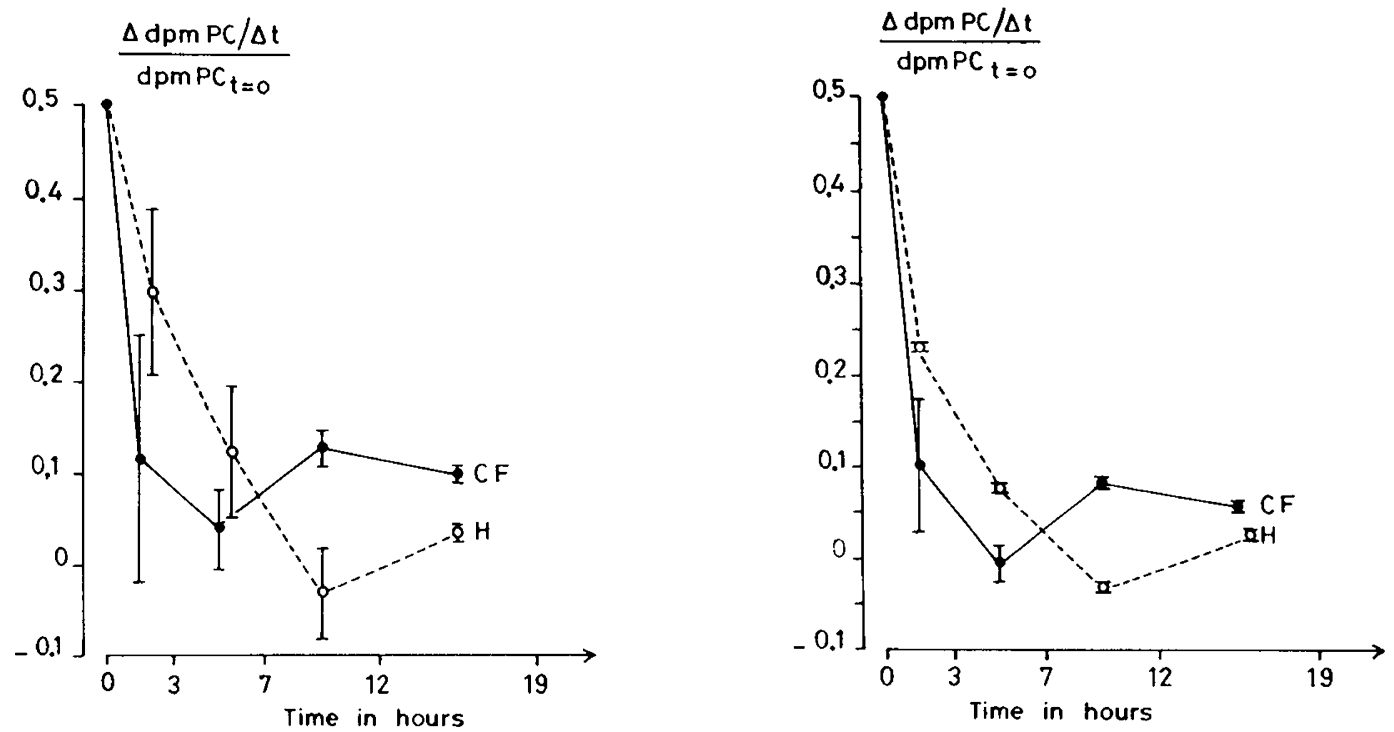

Fig. 5. Relative incorporation rate per time interval $(\Delta t)$ for $\left[{ }^{14} \mathrm{C}\right]$-linoleic (left hand panel) and $\left[{ }^{3} \mathrm{H}\right]$-palmitic acid (right hand panel) into the phosphatidyl choline fraction of the erythrocyte membranes during the reincubation experiment. Results are shown as mean \pm S.D. $(n=4)$, cystic fibrosis and $\mathrm{O}-\mathrm{-}_{--} \mathrm{O}$, healthy children. Experimental conditions are as described in "Materials and Methods," reincubation experiment.
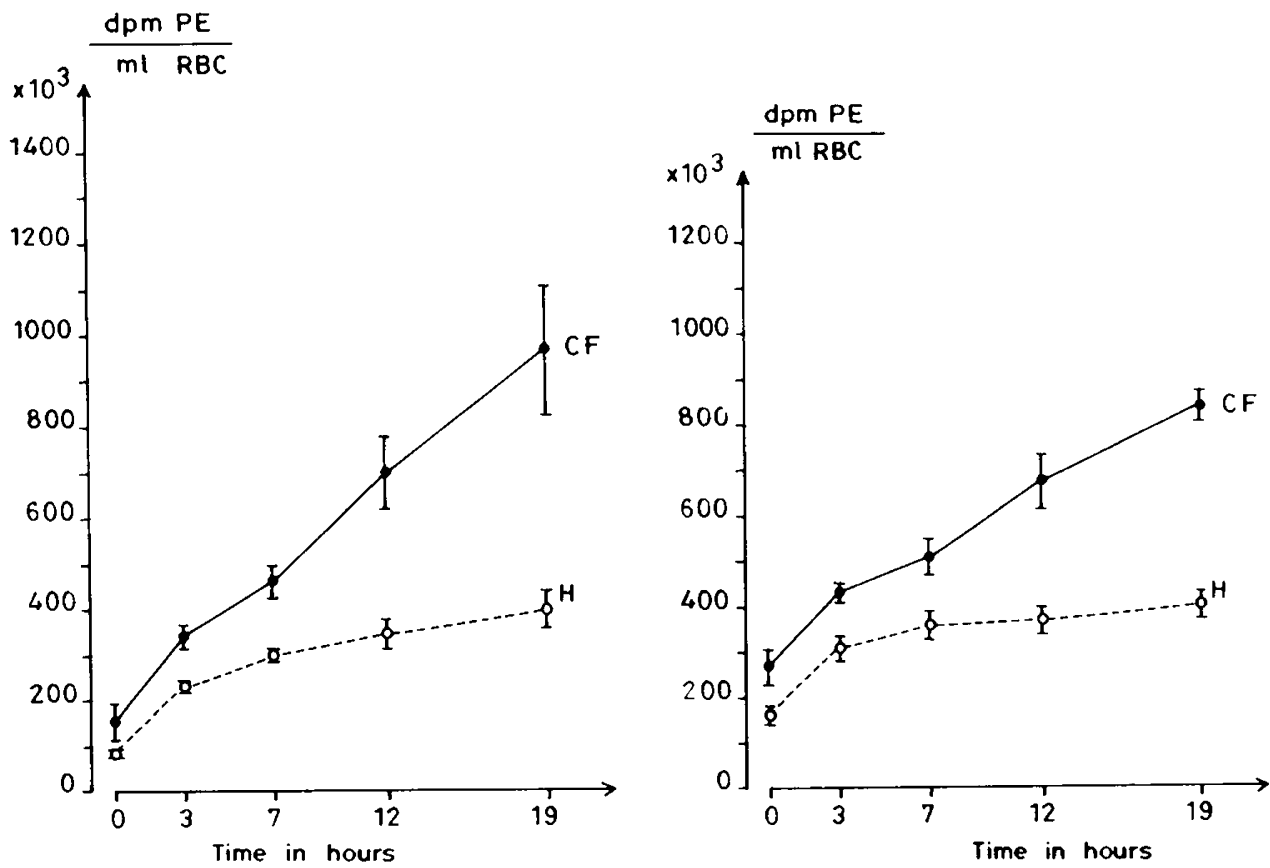

Fig. 6. Further in vitro incorporation of $\left[{ }^{14} \mathrm{Cl}\right.$-linoleic (left hand panel) and of $\left[{ }^{3} \mathrm{H}\right]$-palmitic acid (right hand panel) into the phosphatidyl ethanolamine fraction of erythrocyte membranes during the reincubation experiment. Results are shown as mean \pm S.D. $(n=4)$, O-----O, healthy children. Experimental conditions are as described in "Materials and methods," reincubation experiment.

both labeled fatty acids are incorporated into $\mathrm{PC}$, transferred into $\mathrm{PE}$ and released into the serum at the same rate for both groups of children, the ratio of incorporated $\left[{ }^{3} \mathrm{H}\right]$-palmitic versus $\left[{ }^{14} \mathrm{C}\right]$ linoleic acid is calculated (Fig. 8). The different starting conditions are taken into account.

The curves obtained for $\mathrm{CF}$ and healthy children have the same shape for the RBC PC and PE fractions and for the serum lipids. The curve for healthy children is situated above the one for $\mathrm{CF}$ patients (Fig. 8). At $t=0$ this difference already exists $(P<0.05)$. It is maintained throughout the experiment. At $t=0$, more labeled linoleic acid versus palmitic acid is present in the serum of $\mathrm{CF}$ patients in comparison with healthy children. In other words, $\mathrm{CF}$ erythrocytes retain in their membranes more palmitic than linoleic acid.

\section{DISCUSSION}

The incorporation experiment is run under nearly identical conditions as described by Shohet et al. (30). Glucose, ATP and $\mathrm{CoA}$ SH are added to the incubation medium to stimulate the incorporation of NEFAs into the RBC membranes. The consumption of glucose is fairly constant and is $4 \mathrm{mg} \%$ per $\mathrm{h}$ for both groups of children.

The incorporation of both labeled fatty acids into the PC and $\mathrm{PE}$ fractions of the $\mathrm{RBC}$ membranes is going on with a constant rate for only $2 \mathrm{~h}$ for healthy children (Fig. $2 \mathrm{a}, \mathrm{b}$ and $3 \mathrm{a}, \mathrm{b}$ ). This observation is in agreement with the results of Oliveira and Vaughan (17). Shohet et al. (30), Donabedian and Karmen (6) and Mulder and Van Deenen (15). These investigators have shown 

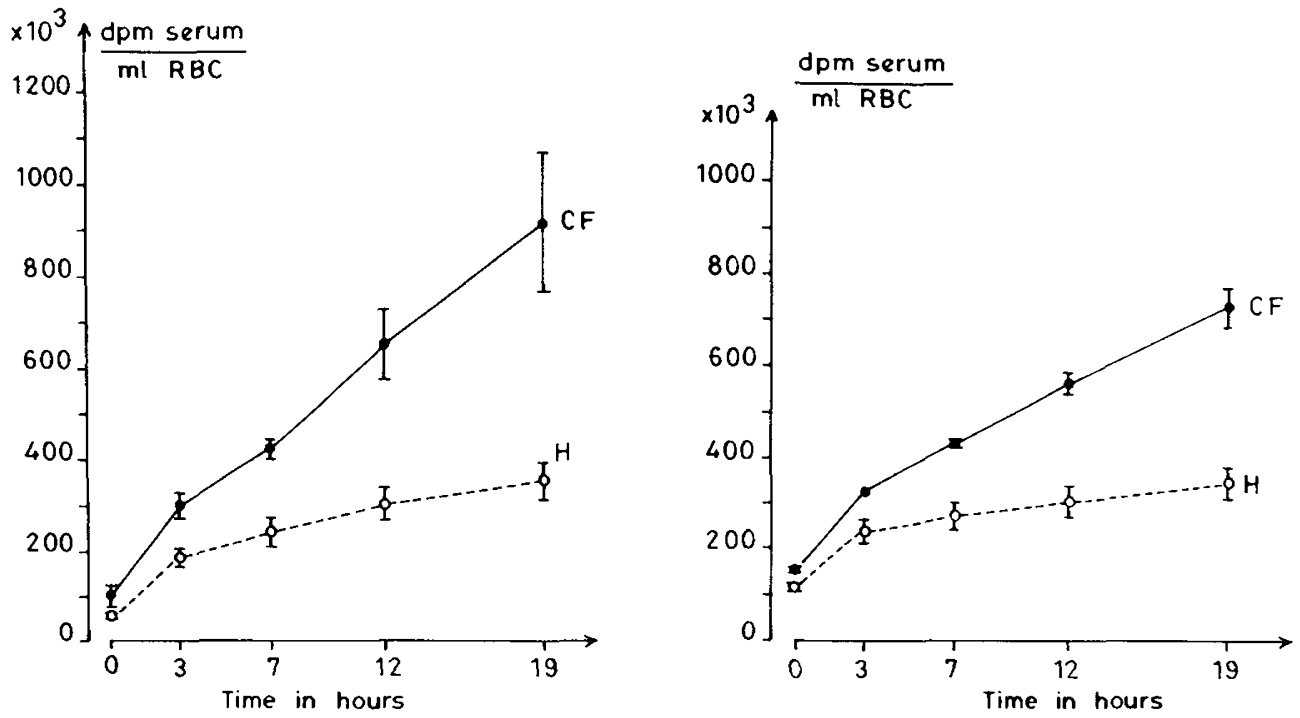

Fig. 7. In vitro release of $\left[{ }^{14} \mathrm{C}\right]$-linoleic (left hand panel) and $\left[{ }^{3} \mathrm{H}\right]$-palmitic acid (right hand panel) from the red blood cell phospholipids into the

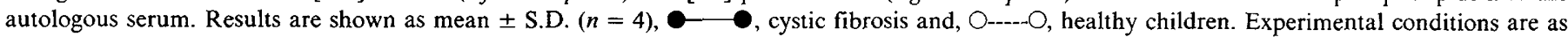
described in "Materials and Methods," reincubation experiment.

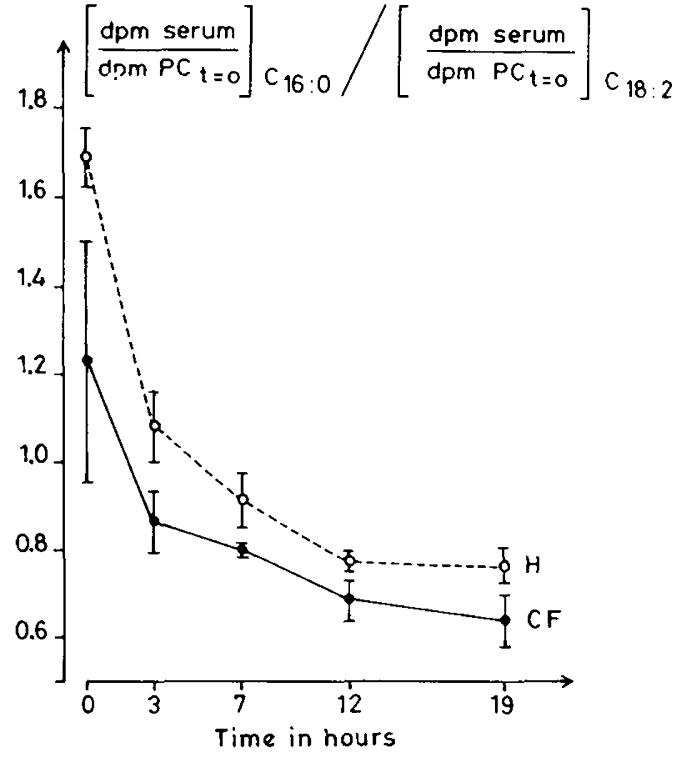

Fig. 8. Ratio of incorporated $\left[{ }^{3} \mathrm{H}\right]$-palmitic versus $\left[{ }^{14} \mathrm{C}\right]$-linoleic acid in the lipids of autologous serum during the reincubation experiment. Results are shown as mean \pm S.D. $(n=4), \longrightarrow$, cystic fibrosis and, O----O, healthy children. Experimental conditions are as described in "Materials and Methods," Reincubation experiment. $\mathrm{C}_{16: 0}$, palmitic acid and $\mathrm{C}_{18: 2 \text {, }}$ linoleic acid.

that for healthy subjects the incorporation slows down after about $3 \mathrm{~h}$. For CF patients we have found that this incorporation process continues at the same rate (Fig. $2 \mathrm{a}, \mathrm{b}$ and $3 \mathrm{a}, \mathrm{b}$ ); however, results of similar work for CF patients do not exist in the literature.

During the whole experiment, the incorporation rate of both labeled fatty acids is higher for $\mathrm{CF}$ patients than for healthy children. Four explanations can be put forward.

(1) It is possible that a difference in pool size $F_{2}$ exists between $\mathrm{CF}$ and healthy RBCs. More information concerning the nature and the size of this deeper membrane pool will be obtained in further experiments.

(2) Lyso-PC, needed for the acyltransferase reaction, could be available in higher concentration in CF cells than in healthy ones. Perhaps lecithin cholesterol acyltransferase might play an important role in the formation of more lyso-PC.
(3) The activity of the various enzyme systems, involved in the active incorporation process, may have changed in CF cells in comparison with healthy ones.

(4) The plasma concentration of vitamin E may be an important factor. It has been reported that the turnover of RBC fatty acids can change when membrane polyunsaturated fatty acids are expose $\_$to higher peroxidation, as in vitamin $\mathrm{E}$ deficiency $(12,16)$. Furthermore the life-span of erythrocytes can be shortened in the case of vitamin $E$ deficiency (7); however, the CF patients examined were supplemented with vitamin $E$ and it is reported that the effects, just mentioned, are reversed with vitamin $E$ therapy (7). The erythrocyte suspensions from the CF patients did not show any hemolysis during the $19 \mathrm{~h}$ reincubation experiment.

The results of the reincubation experiment are in good agreement with those of the incorporation. A general conclusion is that the in vitro turnover of $\left[{ }^{14} \mathrm{C}\right]$-linoleic and $\left[{ }^{3} \mathrm{H}\right]$-palmitic acid in the phospholipid fractions of the $\mathrm{RBC}$ membranes is higher in $\mathrm{CF}$ patients than in healthy children. Furthermore, the RBC of the $\mathrm{CF}$ patients retain in their membranes more $\left[{ }^{3} \mathrm{H}\right]$-palmitic than $\left[{ }^{14} \mathrm{C}\right]$-linoleic acid during this in vitro reincubation experiment.

This assumption can be checked by analysing the ratio of incorporated $\left[{ }^{3} \mathrm{H}\right]$-palmitic versus $\left[{ }^{14} \mathrm{C}\right]$-linoleic acid present at every moment in $\mathrm{PC}$ and $\mathrm{PE}$. This means that the radioactivity that is really present in every spot on the TLC plate is taken into account and not the sum of radioactivities as represented in all the graphs, shown in this paper. It is found that the ratio of incorporated $\left[{ }^{3} \mathrm{H}\right]$-palmitic versus $\left[{ }^{14} \mathrm{C}\right]$-linoleic acid is indeed higher for $\mathrm{CF}$ patients than for healthy subjects. This is true for both the PC (for $t=0$ and $19 \mathrm{~h}, P<0.05$ ) and PE (for $t=0, P$ $<0.01$ and for $t=19 \mathrm{~h}, P<0.001$ ) fractions. Because the ratio mentioned remains constant during the whole experiment, the difference between both groups of children is again observable from the beginning of the experiment.

An acceptable explanation for this observation is the fact that the in vivo fatty acid patterns of the various $\mathrm{RBC}$ phospholipid fractions are abnormal in CF patients with pancreatic insufficiency in comparison with healthy children (24). Namely the \% concentration of palmitic acid is higher and that of linoleic acid lower in RBCs of CF patients. This means that the \% of exchangeable molecules of palmitic versus linoleic acid is significantly higher for the $\mathrm{PC}$ and $\mathrm{PE}$ fractions of CF patients in comparison with healthy subjects.

Consequently we could expect the in vitro ratio of labeled 
palmitic versus linoleic acid in this experiment to be higher in $\mathrm{CF}$ children than in healthy ones.

We can conclude that no difference could be detected between the in vitro incorporation, transfer and release of labeled palmitic acid versus linoleic acid in CF children, compared with healthy ones. During this 19-h experiment, the fatty acid compositions of the $\mathrm{RBC}$ phospholipids remain unchanged.

The increased in vitro turnover of both labeled fatty acids in the $\mathrm{RBCs}$ of $\mathrm{CF}$ patients can be intrinsic to the membrane but may also be caused by extrinsic serum factors. In this study no experiments with standardised serum have been performed in order to try to isolate intrinsic from extrinsic effects. The amount of blood taken from one CF child would have been too high to carry out experiments with autologous and homologous serum simultaneously. In further experiments we will try to answer this question. These experiments may show whether our hypothesis is right or wrong.

If the altered fatty acid composition of the RBCs (24) or the changed turnover of these fatty acids is related to the basic defect in CF, one would hope to be able to detect the same abnormalities in other body fluids and tissues:

(1) Abnormal fatty acid patterns have already been described for the lipids of plasma $(2,9,10,23)$, platelets (20), adipose tissue (11), bronchial mucus (27), and sputum (26) of CF patients with pancreatic insufficiency; however, no difference in fatty acid composition could be detected by Riordan et al. (18) in the plasma membranes of fibroblasts and of cultured lymphoblasts (13). Chase et al. (3) have described a normal fatty acid composition in the three major phospholipid fractions of CF fibroblasts. In previous work we have found that abnormal plasma fatty acid patterns can occur in both $\mathrm{CF}$ patients with and without pancreatic insufficiency $(8,23)$. On the other hand, other investigators have reported normal fatty acid patterns in CF patients without pancreatic insufficiency $(9,10)$.

(2) Recently Chase et al. (3) have reported that fibroblasts of $\mathrm{CF}$ patients cultured with $\left[{ }^{14} \mathrm{C}\right]$-linoleic acid in different media, were able to incorporate more radioactivity into their phospholipid fraction than controls do; however, this was only true for media containing regular fetal calf serum (FCS) and linoleic acid-supplemented FCS. No difference could be observed when delipidated FCS supplemented with linoleic acid was used. In order to interrelate all these observations it is obvious that further research is necessary.

\section{REFERENCES AND NOTES}

1. Bartlett, G. P.: Phosphorus assay in column chromatography. J. Biol. Chem., 234: 466 (1959)

2. Caren, R. and Corbo, L.: Plasma fatty acids in pancreatic cystic fibrosis and liver disease. J. Clin. Endocrinol., 26: 470 (1966)

3. Chase, H. P., Dabiere, C. S., and Elliott, R. B.: Fibroblast fatty acids in cystic fibrosis. Metabolism, 29: 365 (1980).

4. Chase, E. P. and DuPont, J.: Abnormal levels of prostaglandins and fatty acids in blood of children with cystic fibrosis. Lancet, 2: 236 (1978).

5. Chen, R. F.: Removal of fatty acids from serum albumin by charcoal treatment. J. Biol. Chem., 242: 173 (1967).

6. Donabedian, R. and Karmen, A.: Fatty acid transport and incorporation into human erythrocytes in vitro. J. Clin. Invest., 46: 1017 (1967).

7. Farrell, P. M., Bieri, J. G., Fratantoni, J. F., Wood, R. E., and di Sant' Agnese, P. A.: The occurrence and effects of human vitamin E deficiency. J. Clin. Invest., 60: 233 (1977).

8. Faut, A. J., Rogiers. V., and Vercruysse, A.: Vetzuursamenstelling van de cholesterolesterfraktie in plasma van cystic fibrosis patienten. Thesiswork of Faut, A. J.; defined at the Free University Brussels in July 1981, Brussels, Belgium.

9. Galabert, C. Filliat, M., and Chazelette, J. P.: Fatty-acid composition of serumlecithins in cystic fibrosis patients without steatorrhoea. Lancet, 2: 903 (1978).

10. Hubbard, V. S.. Dewey-Dunn, G., and di Sant' Agnese, P. A.: Abnormal fattyacid composition of plasma-lipids in cystic fibrosis. A primary or a secondary defect? Lancet. 2: 1302 (1977).

11. Kuo, P. T., Huang, N. N., and Bassett, D. R.: The fatty acid composition of the serum chylomicrons and adipose tissue of children with cystic fibrosis of the pancreas. J. Pediatr., 60: 395 (1962).

12. Lubin, B. H. and Shohet. S. B.: Alterations in membrane fatty acid turnover in vitamin E deficient erythrocytes during exposure to hydrogen peroxide. Pediatr. Res., 4: 466 (1970).

13. Maler, T. and Riordan, R.: Isolation and characterization of the plasma membranes of cultured lymphoblasts from patients with cystic fibrosis and normal individuals. Biochim. Biophys. Acta, 593: 1 (1980).

14. McEvoy, F. A.: Essential fatty acids and cystic fibrosis. Lancet, 2: 236 (1975)

15. Mulder, E. and Van Deenen, L. L. M.: Incorporation in vitro of fatty acids into phospholipids from mature erythrocytes. Biochim. Biophys. Acta, 106: 106 (1965).

16. Oliveira, M. and Nason, A.: Vitamin E deficiency and fatty acid turnover in erythrocyte membranes. Biochim. Biophys. Acta, 150: 319 (1968).

17. Oliveira, M. M. and Vaughan, M.: Incorporation of fatty acids into phospholipids of erythrocyte membranes. J. Lipid. Res., 5: 156 (1964).

18. Riordan, J. R., Alon, N., and Buchwald, M.: Plasma membrane lipids of human diploid fibroblasts from normal individuals and patients with cystic fibrosis. Biochim. Biophys. Acta, 574: 39 (1979).

19. Robinson, P. G.: 5, 8-11 eicosatrienoic acid in red cells from patients with cystic fibrosis. Proc. 7th. International Cystic Fibrosis Congress held in Paris, France pp. 107-110 (1976).

20. Robinson, P. G. and Dodge, J. A.: Blood cell fatty acids in cystic fibrosis. In Perspectives in cystic fibrosis. Ed: Sturgess, J. M. pp. 3la. Proceedings of the 8th International Cystic Fibrosis Congress held in Toronto, Canada May 2630 (The Imperial Press Ltd., Canada, 1980).

21. Rogiers, V.: The application of an improved gas-liquid chromatographic method for the determination of the long chain non-esterified fatty acid pattern of blood plasma in children. Clin. Chim. Acta, 78: 227 (1977).

22. Rogiers, V.: Gas chromatographic determination of the fatty acid pattern of red cell membrane plasmalogens in healthy children. J. Chrom., 182: 27 (1980).

23. Rogiers, V., Dab, I., Crokaert, R., and Vis, H. L.: Long chain nonesterified fatty acid pattern in plasma of cystic fibrosis patients and their parents. Pediatr. Res., 14: 1088 (1980).

24. Rogiers, V., Crokaert, R., and Vis, H. L.: Altered phospholipid composition and changed fatty acid pattern of the various phospholipid fractions of red cell membranes of cystic fibrosis children with pancreatic insufficiency. Clin. Chim Acta, 105: 105 (1980).

25. Rose, H. G. and Oklander, M.: Improved procedure for the extraction of lipids from human erythrocytes. J. Lipid. Res., 6: 428 (1965).

26. Sahu, S. and Lynn, W. S.: Lipid composition of airway secretions from patients with asthma and with cystic fibrosis. Am. Rev. Resp. Dis., 115: 233 (1977).

27. Sanjurjo, P., Allue, X., and Rodriguez-Soriano, J.: Fatty acid composition of lecithin fraction of mucus in cystic fibrosis. Lancet, $I: 752$ (1977).

28. Shohet, S. B.: Hemolysis and changes in erythrocyte lipids. N. Engl. J. Med. 286: 577 (1972).

29. Shohet, S. B., Livermore, B. M.. Nathan. D. G., and Jaffee, E. R.: Hereditary hemolytic anemia associated with abnormal membrane lipids: mechanisms of accumulation of phosphatidyl choline. blood. 38: 445 (1971).

30. Shohet, S. B., Nathan, D. G., and Karnovsky, M. L.: Stages in the incorporation of fatty acids into red blood cells. J. Clin. Invest., 47: 1096 (1968)

31. Snedecor, G. W. and Cochran, W. G.: Statistical methods, pp. 59, The Iowa State University Press, Iowa, U.S.A. (1967).

32. Sundler, R. and Akesson, B.: Regulation of phospholipid biosynthesis in isolated rat hepatocytes. J. Biol. Chem., 250: 3359 (1975).

33. Umbreit. W. W.: in Data for Biochemical Research, manometric techniques pp 149, Oxford Clarendon Press. Oxford (1959).

34. Vance, D. E. and De Kruijff, B.: The possible functional significance of phosphatidyl-ethanolamine methylation. Nature, 288: 277 (1980).

35. This study has been approved by the ethics committee of the Free University Brussels and blood samples have been obtained only from well informed volunteers.

36. The authors thank Dr. P. Noquin, R. Sion, and M. Pacco (LABAZ, Biochemistry, Brussels) for their most valuable advice and the use of their equipment $J$. DeWit is also thanked for his most efficient technical assistance. Finally, we wish to thank the parents of the $\mathrm{CF}$ and healthy children for their kind cooperation.

37. Requests for reprints should be addressed to: Dr. Vera Rogiers, Vrije Universiteit Brussels, Laboratorium voor Toxicologie, Fakulteit Geneeskunde en Farmacie, Laarbeecklaan, 103, B-1090 Brussels, Belgium.

38. This research was supported by the Medical Foundation "Koningin Elisabeth", the "Belgische Vereniging voor Strijd tegen Mucoviscidose" and the "Nationaal Fonds voor Wetenschappelijk Onderzoek" S 2/5-I.D.E. 37

39. Received for publication February 18, 1981.

40. Accepted for publication February 3, 1982.

\section{NOTE}

The same in vitro experiments with labeled fatty acids, as previously described in detail (1), have been carried out on red blood cells of cystic fibrosis (CF) heterozygotes and of healthy adults. Blood was taken from four obligate heterozygotes, parents of a proven CF child, and from four healthy subjects of the same age group (35-45 years old). As healthy subjects, two couples of at least three children, all in good health, were studied. This in 


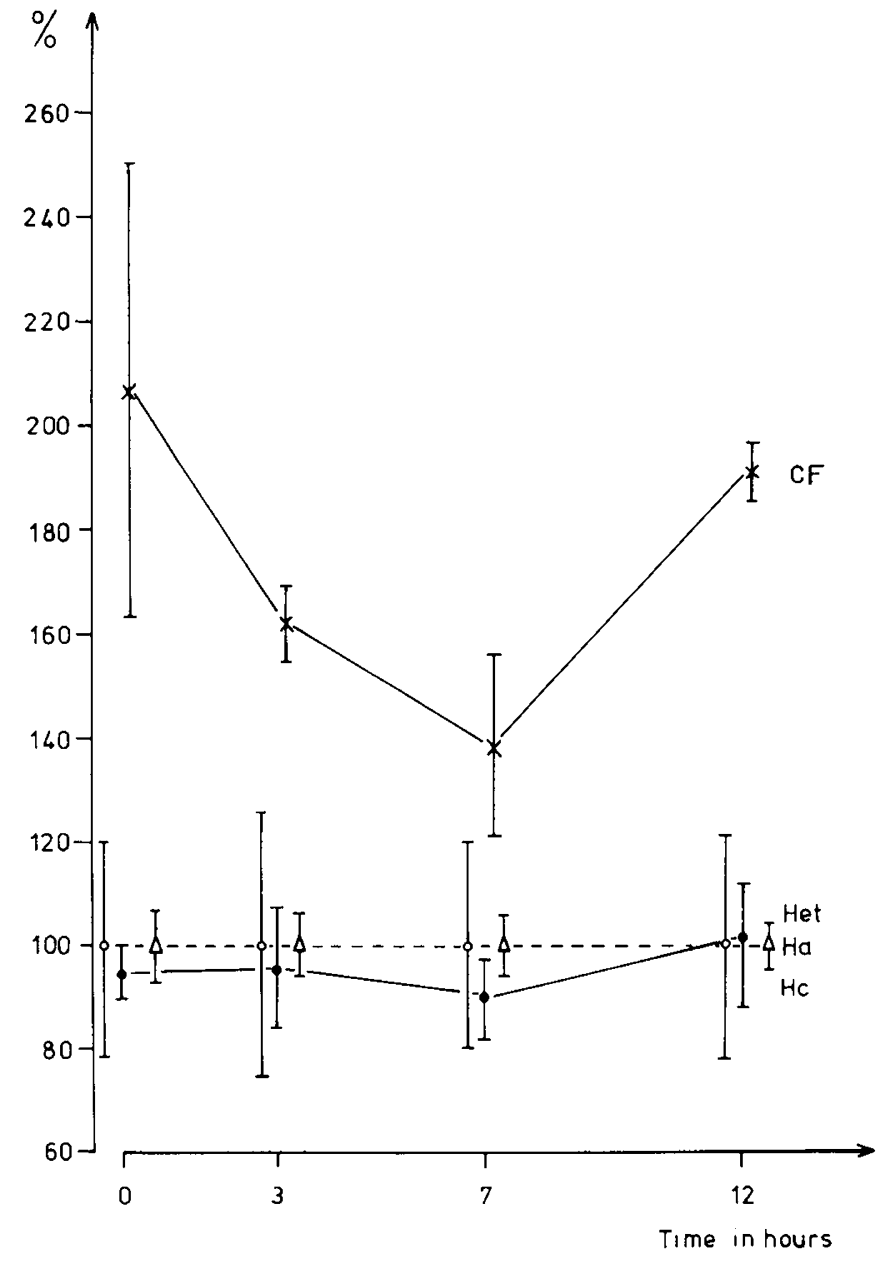

Copyright (C) 1982 International Pediatric Research Foundation, Inc. $0031-3998 / 82 / 1609-0761 \$ 02.00 / 0$ order to minimalise the risk of studying carriers instead of noncarriers.

From the results of the incorporation and reincubation experiments with $\left[{ }^{14} \mathrm{C}\right]$-linoleic and $\left[{ }^{3} \mathrm{H}\right]$-palmitic acid it appeared that in vitro no difference exists between the turnover of both labeled fatty acids in the red cell phospholipids of CF heterozygotes and healthy subjects. This observation can be illustrated by Figure 1 in which part of the results obtained for CF homozygotes and CF heterozygotes are summarized.

1. Rogiers V., Mandelbaum I., Mozes N., Vertongen F., Dab I., Crokaert R. and Vis H. L.: In vitro study of the incorporation and transport of non-esterified fatty acids into the phospholipids of the red blood cell membranes of cystic fibrosis patients. Pediatr. Res., 16: 761 (1982).

Fig. 1. In vitro incorporation of $\left[{ }^{3} \mathrm{H}\right]$-palmitic acid into the phosphatidyl choline fraction of the red cell membranes of CF homozygotes and heterozygotes during the reincubation process. Results for $C F$ patients $(\mathrm{CF}-\times-)$ and $\mathrm{CF}$ carriers (Het- - ) are expressed as \% of the radioactivity present in the phosphatidyl choline fraction of respectively healthy children $(\mathrm{Hc}--\triangle--)$ and healthy adults ( $\mathrm{Ha}--\mathrm{O}--)$. 